\title{
Laterality and language experience
}

\author{
Rachel Hull and Jyotsna Vaid \\ Texas A\&M University, College Station, TX, USA
}

\begin{abstract}
A meta-analysis was conducted on studies that examined hemispheric functional asymmetry for language in brain-intact monolingual and bilingual adults. Data from 23 laterality studies that directly compared bilingual and monolingual speakers on the same language were analysed $(n=1234)$. Variables examined were language experience (monolingual, bilingual), experimental paradigm (dichotic listening, visual hemifield presentation, and dual task) and, among bilinguals, the influence of second language proficiency (proficient vs nonproficient) and onset of bilingualism (early, or before age 6; and late, or after age 6). Overall, monolinguals and late bilinguals showed reliable left hemisphere dominance, while early bilinguals showed reliable bilateral hemispheric involvement. Within bilinguals, there was no reliable effect of language proficiency when age of L2 acquisition was controlled. The findings indicate that early learning of one vs. two languages predicts divergent patterns of cerebral language lateralisation in adulthood.
\end{abstract}

Whereas remarkable progress has been made towards understanding how language is organised in the brain, much of this knowledge has come from studies of single language users and thus does not speak to the situation characterising the majority of the world's language users, who are bilingual or multilingual. Studying the neural concomitants of multiple language experience is important for redressing this gap and, from a broader perspective, to further our understanding of the neurological basis for the capacity for language in its various manifestations.

Existing research on brain lateralisation of language supports the view that the left hemisphere (LH) is dominant for language, particularly for grammatical aspects of language, but that the right hemisphere $(\mathrm{RH})$ also supports language processing, including aspects involved in discourse coherence (e.g., Beeman \& Chiarello, 1998; Boatman, 2004). The present

Address correspondence to: Dr Rachel Hull, Department of Psychology, Texas A\&M University, College Station, Texas 77843-4235, USA. E-mail: rhull@tamu.edu

Portions of this research were presented at the 4th International Symposium on Bilingualism held in Tempe, AZ, 2003. We thank Colin Allen, Winfred Arthur, Heather Bortfeld, Wendy Francis, Michel Paradis, Loraine Obler, Steven M. Smith, Daniel Voyer, and Wendy Wood for constructive comments and/or technical assistance.

(C) 2006 Psychology Press Ltd

http://www.psypress.com/laterality

DOI: $10.1080 / 13576500600691162$ 
research examines whether this generalisation, based largely on the monolingual condition, is equally applicable to users of two or more languages.

There is evidence for distinct cognitive repercussions associated with early exposure to two languages (e.g., Bialystok, 2002; Birdsong \& Molis, 2001; Lambert, 1969). To the extent that the brain is differentially responsive to variations in early sensory experience (Neville \& Bavelier, 2002), one might also expect to find evidence for neural plasticity in response to variations in early language experience. Indeed, findings from a variety of sources have been interpreted to suggest that bilingual language experience may confer unique patterns of neurofunctional activity. For example, one interpretation of case reports for differential language loss or recovery in so-called polyglot aphasics in the neurological literature has been that multiple languages may be organised in spatially distinct neural regions within the languagedominant hemisphere (see Albert \& Obler, 1978; Fabbro, 2001; Ijalba, Obler, \& Chengappa, 2004). In addition, the suggestion that the incidence of crossed aphasia (language deficits following damage to the $\mathrm{RH}$ ) may be higher in bilinguals than in monolinguals has been interpreted as support for greater right hemisphere involvement associated with bilingualism (see Vaid, 2002, for further discussion). Other hints of possible differences in brain organisation of language associated with bilingualism have come from cortical electrical stimulation studies (e.g., Lucas, McKhann \& Ojemann, 2004). Further, electrophysiological studies and laterality studies with brainintact bilinguals have reported deviations from the pattern of LH dominance typically observed in monolinguals, particularly when the variables of language proficiency and age of bilingualism onset are considered (see Hull \& Vaid, 2005).

Several recent neuroimaging studies using haemodynamic measures to assess language activation in brain-intact individuals have examined whether there are distinct or overlapping regions of neural activation for the bilinguals' languages. In general, there is support for overlapping regions of activation, but also some suggestion of individual differences associated with proficiency and/or the age of language acquisition (see Abutalebi, Cappa, \& Perani, 2005; Vaid \& Hull, 2002, for reviews). Finally, at least one neuroimaging study has presented evidence for structural differences in the brain associated with early vs late acquisition of a second language (L2), and with bilingual vs monolingual experience (Mechelli, Crinion, Noppeney, O’Doherty, Ashburner, Frackowiak, et al., 2004).

In light of these various studies, a systematic inquiry is warranted into whether, or under what conditions, multiple language experience has distinct neurofunctional repercussions. The present meta-analysis examined this question by focusing on studies of brain lateralisation of language in healthy bilingual vs monolingual adults. Specifically, the meta-analysis examined whether language lateralisation in bilinguals involves greater reliance on the 
right hemisphere than it does in monolinguals. A related question that was assessed was whether differences in L2 proficiency and/or age of onset of L2 acquisition moderate language lateralisation within bilinguals. Finally, given that different language-testing paradigms may tap into different aspects of language, the present research evaluated whether language lateralisation differs across the three most widely used laterality paradigms; i.e., dichotic listening, tachistoscopic viewing, and dual task performance.

\section{BRAIN FUNCTIONAL ASYMMETRY: WHY MIGHT LANGUAGE EXPERIENCE MATTER?}

Previous studies of second language acquisition and cognitive concomitants of bilingualism, coupled with speculations in the early neurological literature regarding the nature of brain representation for multiple languages, have motivated a number of working hypotheses regarding how language experience might affect language lateralisation (see Hull \& Vaid, 2005; Vaid, 1983, 2002, for further discussion). Two early hypotheses proposed were the second language hypothesis (Genesee, 1982), which predicts that bilinguals in general will be more RH lateralised for language than monolinguals, and the balanced bilingual hypothesis (Galloway, 1983), which posits that proficient bilinguals in particular will show greater $\mathrm{RH}$ participation than monolinguals.

Two other hypotheses - the age of second language acquisition hypothesis (Genesee, Hamers, Lambert, Mononen, Seitz, \& Starck, 1978; Vaid \& Genesee, 1980) and the stage of second language acquisition hypothesis (Albert \& Obler, 1978; Galloway \& Krashen, 1980; Obler, 1981; Schneiderman, 1986) - predict differential language lateralisation according to either the age at which a bilingual acquires the L2, or the degree to which a bilingual masters the L2, respectively.

According to the age hypothesis, the closer in time that the two languages of bilinguals are acquired (and thus the more similar the underlying cognitive and brain maturational states), the more similar their lateralisation will be. In its initial conceptualisation, the age hypothesis also maintained that, to the extent that early bilinguals resemble monolinguals in having acquired their languages early in life, they should show a similar pattern of lateralisation as monolinguals (i.e., left hemisphere dominance); in contrast, late proficient bilinguals (who acquire a second language later in life) should show a divergence in the pattern of lateralisation for $\mathrm{L} 2$ relative to $\mathrm{L} 1$, and relative to the monolingual pattern.

Whereas the age hypothesis focuses more on the effects of the stable, end state of proficiency in L2, the stage hypothesis theorises about hemispheric differences during the process of attaining proficiency in L2. According to the 
stage hypothesis, early stages of L2 learning rely more on contextual cues to meaning, normally subserved by the $\mathrm{RH}$; however, with increasing proficiency in the language, a shift to LH dominance should ensue as syntactic and phonological aspects of L2 processing become more automatic (for a recent theoretical account of this proposed shift, see Ullman, 2001, 2004).

\section{RATIONALE FOR THE PRESENT META-ANALYTIC REVIEW}

Beginning in the 1970s, several dozen laterality studies of brain-intact bilinguals have appeared in the neuropsychological literature. By now there have also been several narrative reviews of such studies, but efforts to summarise this literature in a narrative form have been complicated by the considerable variability in outcomes across studies. Indeed, the outcomes of laterality studies with bilinguals have ranged from $\mathrm{LH}$ effects to bilateral effects to $\mathrm{RH}$ effects. This perplexing variability has prompted some researchers to question the validity of the behavioural techniques used for inferring language laterality (Paradis, 1990, 2003; Sussman \& Simon, 1988; but see Hellige \& Sergent, 1986, and Segalowitz, 1986). However, given the variety of L2 acquisition onset ages and L2 proficiency levels that have been studied, together with a lack of uniformity across studies in participant selection and methods of analysis, the diversity of outcomes in the bilingual laterality literature is not altogether surprising. It is quite likely that inconsistent outcomes across studies are at least in part a result of uncontrolled participant and methodological variables (see Obler, Zatorre, Galloway, \& Vaid, 1982).

One advantage of the technique of meta-analysis is that it systematically disentangles apparent inconsistencies across an empirical literature. Metaanalysis detects underlying patterns across large quantities of disparate data points by standardising statistical outcomes and minimising the influences of researcher bias, paradigm bias, procedural bias, and reliance on particular methodologies, any of which may obscure real effects described by the data (see Rosenthal, 1994; Rosenthal \& DiMatteo, 2001). In addition, metaanalytic reviews provide the benefits of a narrative review, such as comparison and contrast of a variety of theories, while also quantitatively identifying the relationships between individual independent and dependent variables, a feature that is essential for informing the theories that underlie primary research.

Only one previous meta-analysis of the bilingual laterality literature has been reported (Vaid \& Hall, 1991). Interestingly, only about one quarter of studies in that meta-analysis included both bilinguals and monolinguals, perhaps reflecting a belief that it was unnecessary to include monolingual comparison groups, as one presumably "knows" what the outcome would be 
with monolinguals. Further, more than half of the group comparisons that did directly compare monolinguals to bilinguals did so on languages that were in some cases the L1 of the bilingual and in other cases the L2 of the bilingual. In still other cases, the studies collapsed data across different languages for the bilingual participants. The uncontrolled variance that such practices may have introduced, taken together with the small number of bilingual vs. monolingual comparisons available at the time of the Vaid and Hall meta-analysis, were likely contributors to the absence of a reliable difference between bilinguals and monolinguals. However, the comparison within bilinguals as a function of age and proficiency did yield clear results: no differences in lateralisation were found between proficient and nonproficient bilinguals, but a significant difference was found between early and late bilinguals, with the former being less LH lateralised (Vaid \& Hall, 1991).

The present meta-analysis comparing bilinguals and monolinguals was based on a much larger dataset and was carefully restricted to comparisons of bilingual and monolingual groups tested on the same language. ${ }^{1}$ In what follows, we first describe the rationale underlying the classification system used in the present research. Next, we describe the search and selection criteria and data analysis. We then present the results of the meta-analysis and use them to assess language lateralisation hypotheses, and to compare the relative strengths of the moderators tested. Finally, we discuss promising issues for future research that were identified by our findings.

\section{METHOD}

\section{Identification of articles in sample}

The research domain included all studies conducted and/or published through to the end of September 2004. A comprehensive literature search for published and unpublished studies that assessed cerebral lateralisation of language in neurologically healthy individuals was conducted through keyword searches of 19 electronic databases. ${ }^{2}$ The keywords used were

\footnotetext{
${ }^{1}$ Data from neuroimaging and electrophysiological studies were excluded from the metaanalysis because of the inappropriateness of including studies that are incompatible in terms of statistical, methodological, and conceptual grounds (see Lipsey \& Wilson, 2001).

${ }^{2}$ Web of Science version 4.1 forward citation search; Science Citation Index (Expanded) (1982-present) forward citation search; Social Sciences Citation Index (1982-present) forward citation search; Arts and Humanities Citation Index (1982-present) forward citation search; Biology Digest (1989-present); Biological Sciences (1982-present); Digital Dissertations (1861present); ERIC; Linguistic and Language Behavioral Abstracts (1973-present); MedLine (1989present); OVID; PsycINFO; Web Resources Related to the Social Sciences; Alternative Press Index of NISC and Biblioline; Dissertation Abstracts; Sociological Abstracts (1963-present); NTIS; ASFA1: Biological Sciences and Living Resources.
} 
bilingual*, monolingual*, linguistic*, lateral*, hemispher*, and brain. The database searches were supplemented by manual searches of seven periodicals ${ }^{3}$ dated from January 1998 through September 2004, and by citedreference forward searches, author name searches, and personal communication with primary study authors. The various search methods yielded a database of over 100 primary studies that included numerous unpublished works, although the majority of these did not include monolingual participants. Careful review of the study corpus uncovered 23 studies that met all of the inclusion criteria, as specified below.

\section{Operationalisations and sample selection criteria}

The attributes used to define monolingualism, bilingualism, and subtypes of bilingualism have varied from study to study. To generate clear categories of the language-user attributes used to select our sample, the following operationalisations were employed.

- Monolinguals-persons with functional knowledge of only one language.

- Bilinguals-persons with functional knowledge of at least two languages.

- Early bilinguals - bilinguals who acquired both languages before the age of 6 years (and thus, for whom both languages were their L1).

- Late bilinguals - bilinguals who acquired their second language after the age of 6 years.

- Proficient bilinguals - bilinguals whose language performance on standardised language proficiency exams was at or exceeded $85 \%$ accuracy; teacher ratings were high on proficiency; self-ratings were high on proficiency; or there were 5 or more years of formal study of the language.

- Nonproficient bilinguals-bilinguals who did not meet any of the above criteria for proficiency.

The criteria for inclusion in the meta-analysis were as follows: published or unpublished studies that assessed hemispheric involvement on a verbal task in brain-intact monolingual and bilingual adults. Furthermore, where studies involved comparisons of late bilinguals with monolinguals, only those studies in which the language of the monolinguals was the same as the

\footnotetext{
${ }^{3}$ Brain \& Language; Brain \& Cognition; Memory \& Cognition; Journal of Experimental Psychology: Learning, Memory and Cognition; NeuroImage; Psychological Bulletin \& Review; Journal of Memory \& Language.
} 
first language of the late bilinguals were included. In addition, the language that was assessed for early bilinguals always matched the language of the monolinguals and the first language of any late bilinguals who were also included in a given study. Studies were excluded from the sample if they were based on participants who were neurologically impaired, or were native or non-native users of signed language, or if the studies did not assess hemispheric involvement for language, or did not include sufficient quantitative information to enable analysis.

\section{Sample of studies}

In all, 23 behavioural language laterality studies met the inclusion criteria. Of these, 16 were published and 7 were unpublished. A total of 24 statistically independent effect sizes were generated for monolinguals (see Table 1) and 51 for bilinguals (see Table 2).

\section{Variables coded in the sample of studies}

The following information was coded in the primary studies whenever possible: language experience (monolingual, bilingual), age of L2 acquisition (early, late), level of L2 proficiency (proficient, nonproficient), and experimental paradigm (dichotic listening, visual hemifield, dual task). Inter-rater agreement was 94\%, and inconsistencies were resolved through discussion.

The first three moderator variables represent language experience variables and are defined by our operationalisations. In addition, studies were coded according to whether hemispheric involvement was assessed by visual hemifield (V), dichotic listening (DL), or dual task (DT) paradigms. The dichotic listening paradigm measures the recall accuracy or reaction time (RT) of participants' auditory judgements about verbal stimuli simultaneously presented in either ear. The visual hemifield paradigm involves the presentation of a series of written words randomly to the left or right visual field. Greater recall accuracy of stimuli presented to either the left or right ear (or visual hemifield) is used to infer increased contralateral hemispheric involvement. The dual task paradigm is based on decreased motor performance in finger-tapping rates for the hand associated with the hemisphere mediating a concurrent verbal task. Thus, the dependent variable for dual tasks is finger-tapping interference, where hemispheric dominance is inferred when there is a higher interference score in one hand than the other.

One may well ask whether categorising studies according to experimental paradigm alone is precise enough to uncover reliable differences in lateralisation. Aside from differences in paradigm, laterality studies also 
TABLE 1

Data in meta-analysis: Monolingual language laterality

\begin{tabular}{|c|c|c|c|c|c|}
\hline Study author(s), year & $L 1$ & Group $n$ & $d$ & $95 \% C I$ & $\begin{array}{c}\text { Experimental } \\
\text { paradigm }\end{array}$ \\
\hline Chengappa et al. $(2002)^{\mathrm{b}}$ & Kannada & 10 & -1.34 & $-2.31--0.37$ & $\mathrm{~V}$ \\
\hline \multicolumn{6}{|l|}{ Fabbro $\left(1992\right.$, Exp. 4) ${ }^{\mathrm{a}}$} \\
\hline Group 1 & Italian & 10 & 0.20 & $-0.60-1.00$ & DT \\
\hline Group 2 & Italian & 10 & 0.07 & $-0.73-0.87$ & DT \\
\hline Group 3 & Italian & 12 & 0.06 & $-0.99-1.11$ & DT \\
\hline Fabbro et al. $(1990)^{\mathrm{a}}$ & Italian & 14 & 0.02 & $-0.72-0.76$ & DT \\
\hline Fabbro et al. $(1988)^{\mathrm{b}}$ & Italian & 12 & 1.10 & $0.24-1.95$ & DL \\
\hline Furtado \& Webster (1991) ${ }^{a}$ & English & 16 & 0.15 & $-0.54-0.85$ & DT \\
\hline Green $(1986)^{\mathrm{a}}$ & English & 24 & -0.22 & $-0.79-0.35$ & DT \\
\hline \multicolumn{6}{|l|}{ Green et al. $(1990)^{a}$} \\
\hline Group 1 & Spanish & 16 & 0.29 & $-0.41-0.98$ & DT \\
\hline Group 2 & Spanish & 16 & 0.12 & $-0.57-0.82$ & DT \\
\hline \multicolumn{6}{|l|}{ Hynd \& Scott $(1980)^{\mathrm{a}}$} \\
\hline Group 1 & English & 20 & -3.54 & $-4.54--2.55$ & DL \\
\hline Group 2 & English & 20 & -2.75 & $-3.62--1.89$ & DL \\
\hline $\operatorname{Ke}(1992)^{a}$ & English & 24 & 0.38 & $-0.19-0.95$ & DL \\
\hline McClung $(1981)^{\mathrm{b}}$ & English & 30 & 0.52 & $0.00-1.03$ & DL \\
\hline McKeever \& Hunt (Exp. 1, 1984) ${ }^{\mathrm{a}}$ & English & 32 & 0.31 & $-0.18-0.80$ & DL \\
\hline McKeever \& Hunt (Exp. 2, 1984) & English & 102 & 0.75 & $0.46-1.03$ & DL \\
\hline Scott et al. $(1979)^{\mathrm{a}}$ & English & 20 & 1.58 & $0.87-2.29$ & DL \\
\hline \multicolumn{6}{|l|}{ Sewell \& Panou (1983) } \\
\hline Group 1 & English & 6 & 0.31 & $-0.83-1.44$ & $\mathrm{~V}$ \\
\hline Group 2 & English & 6 & 0.35 & $-0.79-1.49$ & V \\
\hline Starck et al. $(1977)^{\mathrm{a}}$ & English & 24 & 0.07 & $-0.49-0.64$ & DL \\
\hline Vaid $(1987)^{\mathrm{a}}$ & English & 16 & 0.32 & $-0.38-1.02$ & $\mathrm{~V}$ \\
\hline Vaid (1984a; Exp. 1) ${ }^{\mathrm{a}}$ & English & 16 & 0.01 & $-0.69-0.70$ & $\mathrm{~V}$ \\
\hline \multicolumn{6}{|l|}{ Vaid (1984a; Exp. 2) ${ }^{\mathrm{a}}$} \\
\hline Group 1 & English & 8 & 0.57 & $-0.43-1.57$ & V \\
\hline Group 2 & English & 8 & 0.45 & $-0.54-1.45$ & V \\
\hline Vaid (1984a; Exp. 3) ${ }^{\mathrm{a}}$ & English & 8 & 0.33 & $-0.66-1.31$ & $\mathrm{~V}$ \\
\hline \multicolumn{6}{|l|}{ Vaid $(1984 b)^{\mathrm{b}}$} \\
\hline Group 1 & French & 12 & 0.31 & $-0.50-1.11$ & V \\
\hline Group 2 & French & 12 & 0.29 & $-0.51-1.10$ & $\mathrm{~V}$ \\
\hline Vaid $(1981 a)^{b}$ & English & 8 & 0.22 & $-0.76-1.21$ & $\mathrm{~V}$ \\
\hline Vaid $(1981 b)^{b}$ & French & 8 & 0.06 & $-0.92-1.04$ & V \\
\hline \multicolumn{6}{|l|}{ Vaid $(1980 a)^{b}$} \\
\hline Group 1 & English & 8 & 0.03 & $-0.95-1.01$ & V \\
\hline Group 2 & English & 8 & -0.06 & $-1.04-0.92$ & $\mathrm{~V}$ \\
\hline Vaid $(1979)^{\mathrm{a}}$ & French & 8 & 0.12 & $-0.86-1.10$ & $\mathrm{~V}$ \\
\hline Vaid et al. $(1989)^{\mathrm{a}}$ & English & 24 & 0.19 & $-0.37-0.76$ & V \\
\hline \multicolumn{6}{|l|}{ Vaid \& Lambert (1979) ${ }^{\mathrm{a}}$} \\
\hline Group 1 & English & 8 & -0.01 & $-0.99-0.97$ & V \\
\hline Group 2 & English & 8 & -0.00 & $-0.98-0.98$ & $\mathrm{~V}$ \\
\hline
\end{tabular}

$\mathrm{CI}=$ confidence interval; Exp. $=$ experiment; $\mathrm{DL}=\mathrm{DL}$ listening; $\mathrm{DT}=$ dual task; $\mathrm{V}=$ visual hemifield. Effect sizes $(d \mathrm{~s})$ reflect greater activation in the left hemisphere when the CIs do not include zero, and bilateral activation when the CIs include zero. ${ }^{a}$ Published study. ${ }^{b}$ Unpublished study. 
TABLE 2

Data in meta-analysis: Bilingual language laterality

\begin{tabular}{|c|c|c|c|c|c|c|c|}
\hline Study author (s), year & $L 1$ & Group $n$ & $d$ & $95 \% C I$ & $\begin{array}{c}\text { Age of } \\
\text { L2 onset }\end{array}$ & L2 proficiency & $\begin{array}{l}\text { Experimental } \\
\text { paradigm }\end{array}$ \\
\hline Chengappa et al. $(2002)^{\mathrm{b}}$ & Kannada & 10 & 0.22 & $-0.66-1.10$ & $\mathrm{~L}$ & Proficient & $\mathrm{V}$ \\
\hline \multicolumn{8}{|l|}{ Fabbro (1992, Exp. 4) } \\
\hline Group 1 & Italian & 12 & 0.20 & $-0.60-1.00$ & E & Proficient & DT \\
\hline Group 2 & Italian & 12 & 0.07 & $-0.73-0.87$ & E & Proficient & DT \\
\hline Group 3 & Italian & 7 & 0.06 & $-0.99-1.11$ & E & Proficient & DT \\
\hline Fabbro et al. $(1990)^{\mathrm{a}}$ & Italian & 14 & 0.02 & $-0.72-0.76$ & $\mathrm{~L}$ & Proficient & DT \\
\hline \multicolumn{8}{|l|}{ Fabbro et al. $(1988)^{\mathrm{b}}$} \\
\hline Group 1 & Italian & 12 & 0.87 & $0.03-1.71$ & $\mathrm{~L}$ & Proficient & DL \\
\hline Group 2 & Italian & 12 & 1.10 & $0.24-1.95$ & $\mathrm{~L}$ & Proficient & DL \\
\hline \multicolumn{8}{|l|}{ Furtado \& Webster (1991) $)^{\mathrm{a}}$} \\
\hline Group 1 & English & 16 & -.08 & $-0.77-0.61$ & E & Proficient & DT \\
\hline Group 2 & English & 16 & 0.15 & $-0.54-0.85$ & $\mathrm{~L}$ & Proficient & DT \\
\hline \multicolumn{8}{|l|}{ Green $(1986)^{\mathrm{a}}$} \\
\hline Group 1 & English & 24 & -0.08 & $-0.64-0.49$ & $\mathrm{~L}$ & Proficient & DT \\
\hline Group 2 & English & 24 & -0.20 & $-0.77-0.36$ & $\mathrm{~L}$ & Nonproficient & DT \\
\hline Group 3 & English & 24 & -0.28 & $-0.85-0.29$ & $\mathrm{~L}$ & Nonproficient & DT \\
\hline \multicolumn{8}{|l|}{ Green et al. $(1990)^{\mathrm{a}}$} \\
\hline Group 1 & Spanish & 8 & 0.46 & $-0.54-1.45$ & $\mathrm{E}$ & Proficient & DT \\
\hline Group 2 & Spanish & 8 & 0.48 & $-0.52-1.47$ & E & Proficient & DT \\
\hline Group 3 & Spanish & 8 & 0.49 & $-0.51-1.48$ & E & Proficient & DT \\
\hline Group 4 & Spanish & 8 & 0.37 & $-0.61-1.36$ & E & Proficient & DT \\
\hline \multicolumn{8}{|l|}{ Hynd \& Scott $(1980)^{\mathrm{a}}$} \\
\hline Group 1 & English & 20 & -3.54 & $-4.54--2.55$ & $\mathrm{U}$ & Nonproficient & DL \\
\hline Group 2 & English & 20 & -2.75 & $-3.62--1.89$ & $\mathrm{U}$ & Nonproficient & DL \\
\hline
\end{tabular}


Table 2 (Continued)

\begin{tabular}{|c|c|c|c|c|c|c|c|}
\hline Study author (s), year & $L 1$ & Group $n$ & $d$ & $95 \% C I$ & $\begin{array}{c}\text { Age of } \\
\text { L2 onset }\end{array}$ & L2 proficiency & $\begin{array}{c}\text { Experimental } \\
\text { paradigm }\end{array}$ \\
\hline \multicolumn{8}{|l|}{$\operatorname{Ke}(1992)^{a, c}$} \\
\hline Group 1 & English & 24 & 0.20 & $-0.33-0.72$ & $\mathrm{~L}$ & Proficient & DL \\
\hline Group 2 & English & 29 & 0.77 & $0.24-1.31$ & $\mathrm{~L}$ & Nonproficient & DL \\
\hline McClung $(1981)^{\mathrm{b}}$ & English & 30 & 0.52 & $0.00-1.03$ & $\mathrm{~L}$ & Proficient & DL \\
\hline McKeever \& Hunt (Exp. 1, 1984) ${ }^{\mathrm{a}}$ & English & 32 & 0.89 & $0.38-1.40$ & $\mathrm{U}$ & Proficient & DL \\
\hline McKeever \& Hunt (Exp. 2, 1984) & English & 32 & 0.82 & $0.31-1.33$ & $\mathrm{U}$ & Proficient & DL \\
\hline \multicolumn{8}{|l|}{ Sewell \& Panou $(1983)^{\mathrm{a}}$} \\
\hline Group 1 & English & 6 & 0.14 & $-0.99-1.28$ & $\mathrm{E}$ & Proficient & $\mathrm{V}$ \\
\hline Group 2 & English & 6 & 0.21 & $-0.93-1.34$ & $\mathrm{E}$ & Proficient & $\mathrm{V}$ \\
\hline Group 3 & English & 6 & 0.45 & $-0.70-1.59$ & $\mathrm{~L}$ & Proficient & $\mathrm{V}$ \\
\hline Group 4 & English & 6 & 0.22 & $-0.91-1.36$ & $\mathrm{~L}$ & Proficient & $\mathrm{V}$ \\
\hline Starck et al. $(1977)^{\mathrm{a}}$ & English & 24 & 0.74 & $0.16-1.33$ & $\mathrm{E}$ & Proficient & DL \\
\hline Vaid $(1987)^{\mathrm{a}}$ & English & 16 & -0.10 & $-0.78-0.59$ & $\mathrm{E}$ & Proficient & $\mathrm{V}$ \\
\hline \multicolumn{8}{|l|}{ Vaid (1984a; Exp. 1) ${ }^{\mathrm{a}}$} \\
\hline Group 1 & English & 4 & -0.08 & $-1.46-1.31$ & $\mathrm{~L}$ & Proficient & $\mathrm{V}$ \\
\hline Group 2 & English & 4 & -0.74 & $-2.17-0.70$ & $\mathrm{~L}$ & Proficient & $\mathrm{V}$ \\
\hline Group 5 & English & 8 & -0.23 & $-1.21-0.76$ & $\mathrm{E}$ & Proficient & $\mathrm{V}$ \\
\hline Group 6 & English & 8 & -0.44 & $-1.43-0.56$ & $\mathrm{E}$ & Proficient & $\mathrm{V}$ \\
\hline Vaid (1984a; Exp. 2) & English & 8 & -0.36 & $-1.35-0.62$ & $\mathrm{E}$ & Proficient & $\mathrm{V}$ \\
\hline \multicolumn{8}{|l|}{ Vaid (1984a; Exp. 3) ${ }^{\mathrm{a}}$} \\
\hline Group 1 & English & 8 & -0.21 & $-1.19-0.78$ & $\mathrm{E}$ & Proficient & $\mathrm{V}$ \\
\hline Group 2 & English & 4 & 0.11 & $-1.27-1.50$ & $\mathrm{~L}$ & Proficient & $\mathrm{V}$ \\
\hline \multicolumn{8}{|l|}{ Vaid $(1984 b)^{b}$} \\
\hline Group 1 & French & 8 & -0.43 & $-1.42-0.56$ & $\mathrm{E}$ & Proficient & $\mathrm{V}$ \\
\hline Group 2 & French & 8 & -0.17 & $-1.16-0.81$ & $\mathrm{E}$ & Proficient & $\mathrm{V}$ \\
\hline
\end{tabular}

(Continued overleaf) 


\begin{tabular}{|c|c|c|c|c|c|c|c|}
\hline Study author (s), year & $L 1$ & Group $n$ & $d$ & $95 \% C I$ & $\begin{array}{c}\text { Age of } \\
\text { L2 onset }\end{array}$ & L2 proficiency & $\begin{array}{c}\text { Experimental } \\
\text { paradigm }\end{array}$ \\
\hline Vaid (1981a) ${ }^{b}$ & English & 8 & 0.17 & $-0.81-1.15$ & $\mathrm{E}$ & Proficient & $\mathrm{V}$ \\
\hline \multicolumn{6}{|l|}{ Vaid $(1981 b)^{b}$} & & \\
\hline Group 2 & French & 8 & 0.41 & $-0.58-1.40$ & $\mathrm{~L}$ & Proficient & $\mathrm{V}$ \\
\hline \multicolumn{8}{|l|}{ Vaid $(1980 a)^{b}$} \\
\hline Group 1 & English & 8 & -0.24 & $-1.22-0.74$ & E & Proficient & $\mathrm{V}$ \\
\hline Group 2 & English & 8 & -0.23 & $-1.21-0.76$ & E & Proficient & V \\
\hline Group 5 & English & 4 & -0.01 & $-1.40-1.38$ & $\mathrm{~L}$ & Proficient & $\mathrm{V}$ \\
\hline Group 6 & English & 4 & 0.29 & $-1.10-1.68$ & $\mathrm{~L}$ & Proficient & $\mathrm{V}$ \\
\hline \multicolumn{8}{|l|}{ Vaid $(1979)^{\mathrm{a}}$} \\
\hline Group 1 & French & 16 & -0.02 & $-0.71-0.68$ & E & Proficient & $\mathrm{V}$ \\
\hline Group 2 & French & 8 & 0.10 & $-0.89-1.07$ & $\mathrm{~L}$ & Proficient & $\mathrm{V}$ \\
\hline Vaid et al. (1989) ${ }^{\mathrm{a}}$ & English & 16 & 0.05 & $-0.64-0.75$ & $\mathrm{E}$ & Proficient & V \\
\hline \multicolumn{8}{|l|}{ Vaid \& Lambert (1979) } \\
\hline Group 1 & English & 8 & -0.03 & $-1.01-0.95$ & E & Proficient & V \\
\hline Group 2 & English & 8 & 0.09 & $-0.89-1.07$ & E & Proficient & $\mathrm{V}$ \\
\hline
\end{tabular}

$\mathrm{CI}=$ confidence interval; Exp. = experiment; $\mathrm{DL}=\mathrm{DL}$ listening; $\mathrm{DT}=$ dual task; $\mathrm{V}=$ visual hemifield; $\mathrm{E}=$ early; $\mathrm{L}=$ late; $\mathrm{U}=$ unstated or mixed. Effect sizes $(d \mathrm{~s})$ reflect greater activation in the left hemisphere when the CIs do not include zero, and bilateral activation when the CIs include zero. ${ }^{\text {a Published }}$ study. ${ }^{b}$ Unpublished study. ${ }^{\mathrm{c}} \mathrm{L} 2$ Acquisition age was not explicitly stated but was inferred from clues in the text or by personal communication with the author(s). 
TABLE 3

Distribution of paradigm types across bilingual acquisition age and bilingual proficiency

\begin{tabular}{lrll}
\hline & Visual & Dual task & Dichotic listening \\
\hline Early bilinguals & 11 studies & 3 studies & 1 study \\
Late bilinguals & 7 studies & 3 studies & 2 studies \\
Unstated age & 0 studies & 0 studies & 3 studies \\
Proficient bilinguals & 11 studies & 5 studies & 7 studies \\
Nonproficient bilinguals & 0 studies & 1 study & 2 studies \\
\hline
\end{tabular}

In some cases, both early and late bilinguals and/or both proficient and nonproficient bilinguals were tested in the same study. Three dichotic listening studies did not specify age of L2 acquisition and were not included in this table or in any early vs late bilingual group comparisons.

differ in the nature of stimuli (e.g., content words vs function words, words vs sentences) and the nature of the task (e.g., word recall, sentence paraphrasing, etc.) that themselves could underlie some of the differences in lateralisation effects observed. We acknowledge that more precision in categorising the types of materials and tasks used across these paradigms would be desirable to address whether any such factors might differentially influence language laterality. Unfortunately, the relatively small number of studies that met our inclusion criteria precluded reliable assessments beyond the three major paradigm categories reported here. ${ }^{4}$ However, a review of the included studies indicates that the majority were fairly homogeneous in terms of the stimuli and tasks used, relying mostly on reaction time or accuracy analyses of word-level stimuli.

A related potential concern is whether a particular paradigm type was over-represented in studies that involved early bilinguals relative to those involving late bilinguals. As shown in Table 3, both early and late bilinguals were most often tested in the visual paradigm ( $73 \%$ and $58 \%$, respectively), next in dual task (20\% and $25 \%$, respectively), and least often in dichotic listening ( $7 \%$ and $17 \%$, respectively). Moreover, about one in three of all studies included both early and late bilinguals on identical tasks and stimuli in the same study. Finally, exactly three dual task studies included early bilinguals and three included late bilinguals. Therefore, we feel it is reasonable to suppose that any idiosyncratic bias in effect sizes that could arise from task or stimulus materials is fairly evenly represented across comparison groups.

To investigate the factors influencing L1 laterality in monolinguals relative to bilinguals, we used a fixed effects computational model with categorical model fitting (Hedges \& Becker, 1986; Hedges \& Olkin, 1985).

\footnotetext{
${ }^{4}$ Caution is advised when interpreting results based on fewer than five data points, and some argue that at least 10 data points are needed (see Arthur, Bennet, \& Huffcutt, 2001; Lipsey \& Wilson, 2001).
} 
This method was chosen based on our intention to reduce unexplained heterogeneity by partitioning broad aggregate levels into the finer levels of categorical moderators identified in the literature. An assumption of this approach is that between-study variance not resulting from the operation of moderating variables is random. ${ }^{5}$

Following the fully hierarchical approach of Voyer (1996), Hedges and Becker (1986), and Hunter and Schmidt (1990), the aggregate effect sizes of monolingual and of bilingual language experience were calculated first, then unexplained heterogeneity of these aggregated effect sizes was addressed by partitioning each collective level (e.g., bilinguals) into each of the a priori moderator levels (e.g., early L2 acquisition age, late L2 acquisition age). The process was repeated until statistical homogeneity was retained, or until cell sizes became too small to analyse further.

\section{Calculation of effect sizes}

The majority of language laterality studies are characterised by direct comparisons of two or more groups, rather than by correlational designs. Accordingly, the effect size statistic used to measure the strength of the independent variables in the present research was Cohen's $d$. All analyses were conducted using Johnson's (1993) DSTAT 1.10 software for the meta-analytic review of research literatures. Following Hedges and Olkin (1985), effect sizes were calculated by taking the difference between the control and experimental means and dividing by the pooled standard deviation, shown algebraically as $\left(M_{1}-M_{2}\right) / \delta$. Group data associated with LH performance (e.g., mean tapping rate with the right hand, listening accuracy with the right ear, or reporting accuracy from the right visual field) were treated as the control condition $\left(M_{1}\right)$, whereas data associated with the $\mathrm{RH}$ were treated as the experimental condition $\left(M_{2}\right)$. A positive effect size was associated with greater LH involvement, a negative effect size with greater $\mathrm{RH}$ activation, and effect sizes near zero with bilateral symmetry. The effect sizes were adjusted for bias in population effect size by converting the raw $g$ s to $d$ s (Hedges \& Olkin, 1985).

Once computed, the effect sizes were weighted by sample size and aggregated into the appropriate divisions of each moderating variable (e.g., one mean effect size represented all bilinguals with early $\mathrm{L} 2$ acquisition). The weighting procedure was used to produce a metric of sampling error that involved multiplying the raw effect size by the reciprocal of its variance. As a

\footnotetext{
${ }^{5}$ An alternative would have been to use a random effects model, which assumes an inherent difference between studies. Given that the sample consisted completely of variations on studies designed specifically to test hemispheric involvement, and the assumption that the bulk of the variance could be explained by moderating variables, the random effects model was rejected as an option.
} 
result, the more reliably estimated effect sizes (i.e., ones with relatively less variance) had more weight in the aggregate analysis. Each aggregated $d$ thus provided a summary of the magnitude and direction of that moderator's effect on functional language laterality. The associated $95 \%$ confidence intervals were calculated to describe the range within which a given effect size was expected to fall $95 \%$ of the time (see Hedges \& Olkin, 1985).

Next, the heterogeneity statistic $(Q)$ was computed for each division of each moderator. The $Q$, or "goodness-of-fit" statistic, represents an approximate chi-square distribution with degrees of freedom $k-1$, where $k$ is the total number of effect sizes in the set. $Q$ indicates whether the $d$ s for a given moderator category are similar enough to be considered one population. ${ }^{6}$ The fixed effect categorical models supplied two types of $Q$ statistics; $Q_{\mathrm{B}}$ tested homogeneity between moderator divisions (e.g., monolingual, bilingual), and $Q_{\mathrm{W}}$ tested homogeneity within a division (e.g., bilingual). Within a categorical model, a significant $Q_{\mathrm{B}}$ statistic indicates that at least two aggregate effect sizes for each division of the moderating variable derive from distinct populations. Therefore, when the $Q_{\mathrm{B}}$ statistic was significant, direct contrasts (using the chi-square distribution with $k-1$ degrees of freedom) were conducted to determine which divisions were significantly different from which others (see Lipsey \& Wilson, 2001). For example, if the $Q_{\mathrm{B}}$ statistic indicated heterogeneity of effect sizes for the categorical model describing paradigms, then direct contrasts were performed between the aggregate $d$ s for the three divisions (visual hemifield, dual task, dichotic listening) to determine which was different from which. If significant differences were found, $Q_{\mathrm{W}}$ was then computed for each group to determine whether variance within each group was homogeneous.

In cases where homogeneity could not be retained in a categorical model for a single moderating variable, it was assumed that at least one additional moderating variable was in operation, and further partitioning was performed in an attempt to account for the unexplained variance. That is, categorical models with all combinations of two moderators (e.g., language experience and paradigm) were calculated, then three moderators, and so forth, until homogeneity was retained, moderator categories were exhausted, or cell sizes became too small to yield reliable results. Importantly, the power of $Q$ to detect heterogeneity is compromised when categorical models are based on very small numbers of effect sizes (e.g., Lipsey \& Wilson, 2001). Therefore, a common population effect was concluded only when $Q$ indicated homogeneity and when cell sizes were adequate (e.g., Arthur et al., 2001; Lipsey \& Wilson, 2001).

\footnotetext{
${ }^{6}$ In fixed effects categorical models, it is appropriate to make conclusions concerning the divisions of the moderating variables that have been coded from the included studies (cf. Wood \& Quinn, 2003).
} 
TABLE 4

Mean effect size estimates for moderators of monolingual laterality

\begin{tabular}{lcccccc}
\hline $\begin{array}{l}\text { Moderator } \\
\text { levels }\end{array}$ & $k$ & $\begin{array}{c}\text { Total sample } \\
\text { size } n\end{array}$ & $\begin{array}{c}\text { Mean weighted } \\
d\end{array}$ & $95 \%$ CI & $\begin{array}{c}\text { Mean } \\
\text { uneighted } \\
d\end{array}$ & $\begin{array}{c}\text { Heterogeneity } \\
\text { statistic } Q_{\mathrm{W}}\end{array}$ \\
\hline $\begin{array}{l}\text { Overall } \\
\text { dataset }\end{array}$ & 35 & 584 & 0.37 & $0.25-0.49$ & 0.27 & $60.70^{*}$ \\
$\begin{array}{l}\text { Monolingual dataset partitioned by experimental paradigm } \\
\begin{array}{l}\text { Visual } \\
\text { preference }\end{array}\end{array}$ & 17 & 158 & 0.02 & $-0.21-0.24$ & -0.01 & 12.60 \\
$\begin{array}{l}\text { Dichotic } \\
\text { listening }\end{array}$ & 9 & 284 & 0.68 & $0.51-0.85$ & 0.73 & $23.51^{*}$ \\
Dual task & 9 & 142 & 0.07 & $-0.16-0.31$ & 0.08 & 1.92 \\
\hline
\end{tabular}

${ }^{*} p<.05, d f=k-1 ; k=$ number of independent effect sizes; $\mathrm{CI}=$ confidence interval. Positive effect sizes $(d \mathrm{~s})$ reflect greater activation in the left hemisphere when the CIs do not include zero, and bilateral activation when the CIs include zero.

\section{RESULTS}

The present meta-analysis used fixed effects categorical modelling to partition variance in aggregate effect sizes into homogeneous categories, thereby identifying the sources of unexplained variance that address substantive issues in cognitive language research. Aggregate effect sizes for broad categories (e.g., monolinguals overall), as expected, were not homogeneous but are presented to illustrate how categorical modelling accounted for the unexplained variance. It is critical to note that only the aggregate effect size $(d)$ of models that retained homogeneity can be considered descriptive of that sample. Furthermore, although all possible combinations of moderators were entered in all possible orders, only those categorical models that explain the most variance-and thus have the greatest explanatory value-are presented and discussed.

\section{Moderators of monolingual language laterality}

The fixed effects estimate of language laterality showed that monolinguals as a group were moderately ${ }^{7} \mathrm{LH}$ dominant for language, $d=0.41,95 \%$ Confidence Interval $(\mathrm{CI})=0.28-0.54, k=24$. However, homogeneity was not retained within the monolingual group, $Q_{\mathrm{W}}(23)=57.04, p<.001$; thus further moderator analyses were statistically warranted and were carried out

\footnotetext{
${ }^{7}$ Following Cohen (1992), $d \mathrm{~s}$ of 0.20, 0.30, and 0.50 represent small, medium, and large effect sizes, respectively.
} 
according to the a priori moderators set forth in this meta-analysis (see Table 4).

\section{Experimental paradigm}

For the three levels of experimental paradigm (visual hemifield, dichotic listening, dual task), the fixed effects estimate of monolingual effect sizes revealed that the degree of lateralisation differed, as indicated by the significant heterogeneity statistic, $Q_{\mathrm{W}}(23)=63.42, p<.001$. Specifically, a large $\mathrm{LH}$ effect was obtained for dichotic listening $(k=9 ; d=0.68,95 \%$ CI $0.51-0.85)$, whereas visual hemifield preference $(k=6 ; d=0.01,95 \% \mathrm{CI}$ $-0.35-0.37)$ and dual task designs $(k=9 ; d=0.07,95 \% \mathrm{CI}-0.16-0.31)$ both showed similar patterns of bilateral involvement, $Q_{\mathrm{B}}(1)=0.08$, $n$ s. Moreover, both visual hemifield preference, $Q_{\mathrm{B}}(1)=10.89, p<.01$, and dual task paradigms, $Q_{\mathrm{B}}(1)=16.98, p<.01$, were significantly less $\mathrm{LH}$ lateralised than dichotic listening. Interestingly, homogeneity was retained for hemifield preference and dual tasks, $Q_{\mathrm{W}}(5)=9.21$, $n s$ and $Q_{\mathrm{W}}(8)=1.92$, $n s$, respectively, but considerable variance remained unexplained for dichotic listening, $Q_{\mathrm{W}}(8)=23.51, p<.01$. These results indicate that the bilateral finding for visual hemifield preference and dual tasks is robust and consistent across monolingual participants, whereas monolinguals vary in the lateralisation of verbal processing during dichotic listening tasks. Further investigation into what additional moderator(s) could be responsible for the unexplained variance in dichotic listening studies was not possible, as the set of dichotic listening studies was too small to partition further and still yield reliable results.

\section{Summary of meta-analytic findings for monolinguals}

The following outcomes represent statistically reliable findings for the independent monolingual subgroups for which within-group homogeneity was retained:

- Monolinguals overall showed bilateral involvement on the visual hemifield preference and dual task paradigms, and performance on both paradigms showed less LH lateralisation than did performance on the dichotic listening paradigm.

\section{Moderators of bilingual language laterality}

The fixed effects estimate of first language laterality revealed that bilinguals as a group showed bilateral hemispheric involvement $(d=0.08$, 
TABLE 5

Mean effect size estimates for moderators of bilingual L1 laterality

\begin{tabular}{|c|c|c|c|c|c|c|}
\hline Moderator levels & $k$ & $\begin{array}{l}\text { Total sample } \\
\text { size } n\end{array}$ & $\begin{array}{c}\text { Mean } \\
\text { weighted d }\end{array}$ & $95 \% C I$ & $\begin{array}{c}\text { Mean } \\
\text { unweighted } \\
d\end{array}$ & $\begin{array}{l}\text { Heterogeneity } \\
\text { statistic } Q_{\mathrm{W}}\end{array}$ \\
\hline Overall dataset & 51 & 650 & 0.08 & $-0.04-0.19$ & -0.03 & $172.43^{*}$ \\
\hline \multicolumn{7}{|c|}{ Bilingual dataset partitioned by L2 acquisition age } \\
\hline Early & 25 & 233 & 0.00 & $-0.18-0.19$ & 0.01 & 6.86 \\
\hline Late & 20 & 277 & 0.28 & $0.11-0.45$ & 0.24 & 22.86 \\
\hline Unstated/Mixed & 6 & 140 & -0.29 & $-0.56--0.02$ & -1.07 & $129.32 *$ \\
\hline \multicolumn{7}{|c|}{ Bilingual dataset partitioned by L2 proficiency } \\
\hline Proficient & 45 & 523 & 0.18 & $0.06-0.30$ & 0.10 & $68.60^{*}$ \\
\hline Nonproficient & 6 & 127 & -0.43 & $-0.70--0.16$ & -0.97 & $87.88^{*}$ \\
\hline \multicolumn{7}{|c|}{ Bilingual dataset partitioned by experimental paradigm } \\
\hline Visual preference & 24 & 182 & -0.04 & $-0.25-0.16$ & -0.04 & 6.03 \\
\hline Dichotic listening & 13 & 271 & 0.20 & $0.02-0.39$ & -0.17 & $157.96^{*}$ \\
\hline Dual task & 14 & 197 & 0.03 & $0.17-0.23$ & 0.12 & 5.13 \\
\hline
\end{tabular}

${ }^{*} p<.05, d f=k-1 ; k=$ number of independent effect sizes; $\mathrm{CI}=$ confidence interval; $\mathrm{L} 2=$ second language. Positive effect sizes $(d s)$ reflect greater activation in the left hemisphere when the CIs do not include zero, and bilateral activation when the CIs include zero.

$95 \% \mathrm{CI}=-0.04,-0.19, k=51)$ for the same languages in which monolinguals had been tested. As expected, homogeneity was not retained within bilinguals overall, $Q_{\mathrm{W}}(50)=172.43, p<.001$. Therefore, statistically warranted moderator analyses were conducted to address the unexplained variance (see Table 5).

\section{Experimental paradigm}

Categorical modelling by experimental paradigm revealed laterality differences in bilinguals that mirrored those of monolinguals. Specifically, bilinguals showed bilateral hemispheric involvement on the visual hemifield paradigm $(k=24 ; d=-0.04,95 \% \mathrm{CI}-0.25-0.16)$ and on the dual task paradigm $(k=14 ; d=0.03,95 \%$ CI $-0.16-0.23)$, but showed LH dominance on the dichotic listening paradigm $(k=13 ; d=0.20,95 \%$ CI $0.02-$ $0.39)$. Homogeneity was retained within both visual hemifield preference, $Q_{\mathrm{W}}(23)=6.03, n s$, and dual task paradigms, $Q_{\mathrm{W}}(13)=5.13$, $n s$, whereas homogeneity was not retained within the dichotic listening paradigm, $Q_{\mathrm{W}}(12)=157.96, p<.01$. Unlike monolinguals, however, the LH effect for dichotic listening was not significantly different from the bilateral effects for visual hemifield preference and dual task, as homogeneity was retained across the three paradigms for bilinguals, $Q_{\mathrm{B}}(2)=3.32$, $n s$. 
Further partitioning of the unexplained variance within bilingual dichotic listening was carried out by levels of L2 proficiency and by L2 acquisition age. Modelling of L2 proficiency levels revealed that proficient bilinguals, like monolinguals, showed a moderately large LH effect $(k=10 ; d=0.44, \mathrm{CI}$ $0.24-0.65$ ) for dichotic listening, but homogeneity was not retained, $Q_{\mathrm{W}}(9)=48.81, p<.001$. Only three data points were available for the nonproficient group, so further modelling could not be reliably carried out.

Categorical modelling of dichotic listening effect sizes by L2 acquisition age could not be carried out for early bilinguals, as there were only two such data points. For late bilinguals, performance on the dichotic listening paradigm was strongly LH dominant $(k=6 ; d=0.63,95 \%$ CI $0.38-0.88)$, and homogeneity was retained, $Q_{\mathrm{W}}(5),=4.28, n s$. These results showed that L2 acquisition age was sufficient to account for all dichotic listening variance in late bilinguals when the performance of early bilinguals was removed, suggesting a difference in language laterality for early and late bilinguals as assessed by the dichotic listening paradigm.

\section{Stage of second language acquisition (L2 proficiency)}

Given that the stage hypothesis and the balanced bilingual hypothesis predict specific differences in bilingual language lateralisation as a function of L2 proficiency, and that a marked difference in language lateralisation should be evident in nonproficient relative to proficient groups, we computed fixed effects estimates for each group.

Proficient bilinguals $(k=45)$ showed a small LH effect for language overall $(d=0.18,95 \%$ CI $0.06-0.30)$, but the heterogeneity statistic was significant, $Q_{\mathrm{W}}(44)=68.59, p<.05$. Nonproficient bilinguals $(k=6)$ showed a considerable RH effect $(d=-0.43,95 \%$ CI $-0.70,-0.16)$, and homogeneity was again rejected, $Q_{\mathrm{W}}(5)=87.88, p<.001$. It is important to reiterate here that there were only six data points for nonproficient bilinguals, thus the RH effect may not be reliable (see Arthur et al., 2001). Moreover, the unexplained variance that remained in both groups after partitioning by L2 proficiency weakens the explanatory value of L2 proficiency as a moderator of language laterality in bilinguals.

\section{Age of second language acquisition}

Categorical modelling by L2 acquisition age showed LH dominance for late bilinguals $(k=20 ; d=0.28,95 \%$ CI $0.11-0.45)$, and a bilateral effect for early bilinguals $(k=25 ; d=0.00,95 \% \mathrm{CI}-0.18-0.19)$. Homogeneity was retained within each group, $Q_{\mathrm{W}}(19)=22.86, n s, Q_{\mathrm{W}}(24)=6.86$, $n s$, respectively, indicating that all effect size estimates drawn from the set of early 
bilinguals derived from the same population, and likewise for the set of late bilinguals. Moreover, the between-groups heterogeneity statistic revealed a significant laterality difference between early and late bilinguals, $Q_{\mathrm{B}}(1)=$ $4.79, p<.05$. Importantly, these results mean that (a) no moderators other than L2 acquisition age were needed to explain heterogeneity of language laterality effect sizes within bilinguals, and (b) early bilinguals were less LH lateralised for language than late bilinguals.

\section{Summary of meta-analytic findings for bilinguals}

The following outcomes represent statistically reliable findings for the independent bilingual subgroups for which within-group homogeneity was retained:

- Early bilinguals showed bilateral hemispheric involvement.

- Late bilinguals were LH dominant.

- Bilinguals as a group showed bilateral involvement for visual field and dual task paradigms.

\section{Comparisons between monolingual and bilingual categorical models}

Direct comparisons showed that monolinguals and bilinguals differed in terms of overall hemispheric participation when processing the same language using the same language tasks, $Q_{\mathrm{B}}(1)=14.72, p<.001$. Specifically, monolinguals as a group were LH dominant for language, whereas bilinguals as a group showed bilateral hemispheric involvement for language. In addition to significant differences between the two groups, monolinguals and bilinguals also differed within each language experience group. Moderator analyses were conducted to detect whether any of the theoretically identified moderators of language lateralisation interacted with monolingual and bilingual language experience.

With respect to behavioural testing paradigms, the overall patterns of language lateralisation among monolinguals and bilinguals were quite similar. The two groups showed a similar degree of bilateral hemispheric involvement when performing verbal tasks using the dual task, $Q_{\mathrm{B}}(1)=0.06$, $n s$, and visual hemifield paradigms, $Q_{\mathrm{B}}(1)=0.06$, $n s$. Likewise, both monolinguals and bilinguals were LH lateralised during dichotic listening tasks, although monolinguals showed significantly more LH dominance for dichotic listening than bilinguals, $Q_{\mathrm{B}}(1)=14.01, p<.001$. Another similarity between monolinguals and bilinguals emerged in terms of variance explained among the three paradigms, namely, homogeneity was retained within both 
language experience groups for dual task and visual hemifield preference paradigms. However, unexplained variance remained for monolinguals in dichotic listening tasks, while homogeneity was retained in bilingual groups.

\section{DISCUSSION}

The capacity to produce and understand language is one of our most important human abilities. Given the predominance of multiple language users in the global population, there is a need to understand the effects of exposure to and use of two languages on the development of language representations in the brain. The present research reviewed studies that directly evaluated language lateralisation in monolinguals and bilinguals. The meta-analysis tested four hypotheses that make predictions about language lateralisation for monolinguals and bilinguals. How did these hypotheses hold up against the meta-analytic findings?

\section{The second language hypothesis}

The second language hypothesis predicts that bilinguals in general will show increased RH involvement (or decreased LH laterality) for language relative to monolinguals. The meta-analysis reveals that early bilinguals (and possibly nonproficient bilinguals) did indeed show an absence of LH dominance, but late proficient bilinguals were reliably LH lateralised. Therefore, the meta-analytic results support the second language hypothesis at least for early bilinguals, and possibly also for nonproficient bilinguals to the extent that meta-analytic outcomes from six data points can be considered reliable.

\section{The balanced bilingual hypothesis}

The balanced bilingual hypothesis predicts that proficient speakers of more than one language will process both languages with greater $\mathrm{RH}$ involvement than monolinguals. The meta-analysis reveals that early (proficient) bilinguals do indeed show more bilateral participation than monolinguals during language processing. However, late proficient bilinguals show LH dominance for their first language, and the LH effect does not differ from that of monolingual speakers of that language, $Q_{\mathrm{B}}(1)=0.25$, $n s$. Therefore, the present results support the balanced bilingual hypothesis only in the case of bilinguals who acquire both languages during early development. 


\section{Stage of second language acquisition hypothesis}

The stage hypothesis predicts that LH involvement for language will increase with L2 proficiency. The meta-analytic results suggest that nonproficient bilinguals may be RH lateralised (although the sample size was small), and that proficient bilinguals are indeed LH dominant, but only when the L2 is acquired after the age of 6 . That is, when both languages are acquired early, proficiency in L2 is not associated with LH dominance; thus, the stage hypothesis is supported only for late bilinguals. Nevertheless, the findings of $\mathrm{RH}$ dominance for nonproficient bilinguals and $\mathrm{LH}$ dominance for proficient (late) bilinguals are consistent with the idea that functional organisation for language may actually shift from an initial RH control to a later LH dominance as L2 proficiency increases, at least for late bilinguals (e.g., Ullman, 2001, 2004).

\section{Age of second language acquisition hypothesis}

The prediction that an L2 learned later in life will be lateralised differently from an L1 could not be tested, as only the first language of late bilinguals was assessed. However, in the case of early bilinguals, either language could be considered the L1. It is interesting to note that while early bilinguals showed bilateral activation of the language in which they were assessed (which was the same language as the L1 of the comparison group), monolinguals were reliably left lateralised. Thus, contrary to some previous assumptions, early bilinguals do not resemble monolinguals in their lateralisation pattern. Rather, late bilinguals are more similar to monolinguals in that both groups showed reliable left hemisphere dominance (for their L1).

In summary, with respect to the age hypothesis, our findings corroborate those of the previous meta-analysis by Vaid and Hall (1991) in showing that early and late bilinguals demonstrated different patterns of lateralisation, with early bilinguals showing less lateralisation, and indeed, more bilateral involvement, relative to late bilinguals. Further, our findings clearly establish that early bilinguals are also significantly different from monolinguals in their lateralisation pattern whereas late bilinguals (in their L1) are not.

The present results make clear that hemispheric lateralisation for language is differentially influenced by early language experience, but laterality studies cannot address differences within the hemispheres. Several dozen neuroimaging studies with bilinguals have appeared, and most of these have sought to determine whether neural regions activated for the two languages of bilinguals are spatially distinct or overlap. Indeed, of the 40 or so PET and fMRI studies that have appeared over the past decade, we were 
able to identify only six that specifically measured and reported quantitative data regarding functional asymmetry of the bilinguals' languages (see Hull \& Vaid, 2005). Furthermore, most bilingual neuroimaging studies to date have used very small samples and have not systematically examined effects of the bilingual language acquisition context, relying at best on comparisons of selected individuals who differed in proficiency or age of onset of bilingualism.

Nevertheless, some tentative conclusions from haemodynamic neuroimaging studies have been proposed (see Abutalebi et al., 2005; Vaid \& Hull, 2002). With respect to imaging studies in general, the set of regions that are active during language processing is larger and more variable than that typically observed from lesion-deficit data (e.g., Binder \& Price, 2001; Price, 1998), and right hemisphere regions are activated far more than would be expected on the basis of the monolingual lesion data (e.g., Braun, Guillemin, Hosey, \& Varga, 2001; Hickok, 2001). With respect to bilingual neuroimaging studies, regions of overlapping activation in the two languages appear to characterise early bilinguals (Chee, Hon, Lee, \& Soon 2001; Chee et al., 2000; Horwitz, Amunts, Bhattacharya, Patkin, \& Braun, 2001; Urbanik, Binder, Sobiecka, \& Kozub, 2001), whereas activation of additional left hemisphere regions for the second language relative to the first language appears to characterise late bilinguals (Kim, Relkin, Lee, \& Hirsch, 1997; Klein, Zatorre, Milner, Meyer, \& Evans, 1994). These imaging results correspond with our finding of differential language lateralisation in early and late bilinguals. Moreover, they suggest that late-learned second languages may engage a more variable (but still left hemisphere dominant) neural network.

Whereas the present meta-analysis focused only on studies involving behavioural measures of language lateralisation, there are lessons to be drawn from this review in interpreting the rapidly expanding neuroimaging literature that has tested bilinguals. The value of imaging studies will increase to the extent that they are designed in ways that acknowledge and systematically examine the heterogeneity of bilingual language experience. The current synthesis of findings from behavioural methodologies underlines the importance of basing research questions, including those from neuroimaging studies, on theoretically grounded hypotheses drawn from research in bilingualism, and of systematically testing variables by including appropriate bilingual and monolingual comparison groups, rather than concluding that acquisition age or proficiency does (or does not) matter on the basis of the performance of a subset of participants.

In addition to the importance of considering the full range of participant variables, the present results make clear the consequence methodological differences can have on the apparent consistency of outcomes in an emerging research literature. The systematic examination of effect sizes arising from 
the three most widely used behavioural measures of language lateralisation (i.e., visual hemifield, dichotic listening, and dual task) suggests that the direction of laterality effects may indeed be influenced by the testing paradigm itself. Specifically, dichotic listening tends to elicit a bias towards greater left hemisphere participation relative to either dual task or visual preference, regardless of whether the participants were monolingual or bilingual, and regardless of bilingual L2 acquisition age. We suggest that processing speech sounds, as is demanded in dichotic listening but not necessarily in visual hemifield viewing or dual tasks, preferentially recruits left hemisphere involvement. In this case, dichotic listening measures of laterality may reflect a substantive (rather than idiosyncratic) reason for the difference between this and the other two paradigms in the present research. Another important difference is that unexplained variance within the dichotic listening paradigm is high relative to other paradigms. One possibility is that differences in stimulus and task parameters are creating substantial unexplained variance in the dichotic listening paradigm; these variables need to be systematically examined for all three paradigms as more data points become available. In summary, whether substantive or idiosyncratic, differences emerging from paradigm choice have likely contributed to the diversity of effect sizes reported in the behavioural language laterality literature.

\section{CONCLUSIONS}

The present research provides new evidence for important commonalities and differences in the functional organisation of language in bilingual and monolingual brains. The outcomes demonstrate that the four moderators we tested (i.e., language experience, experimental paradigm, age of L2 acquisition, and stage of L2 acquisition) varied in their influence on the functional cerebral organisation of language, allowing some conclusions to be drawn regarding the relative explanatory values of each. Partitioning effect size variance into the categories of experimental paradigm was useful for explaining variance within monolinguals, whereas partitioning by L2 acquisition age explained variance within bilinguals. Thus, the careful categorical modelling used in the present research highlights the differential influences of language laterality moderators and underlines the importance of considering their individual effects when designing empirical studies and making conclusions about language laterality.

Perhaps the most striking finding from the present research is that late bilinguals (in their L1) were more similar to monolinguals than to early bilinguals. Although some proposals in the bilingual laterality literature have suggested a less lateralised pattern when both languages are acquired early 
(e.g., Birdsong \& Molis, 2001; Goral, Levy, \& Obler, 2002; Hull \& Vaid, 2005; Long, 1990; Vaid, 1987; Vaid \& Hall, 1991), many bilingual cognitive theories have assumed that early language learning will follow the established (left lateralised) monolingual pattern, and that only later learned languages will have be handled differently (e.g., Dijkstra \& Van Heuven, 2002; Genesee et al., 1978; Kroll \& Stewart, 1994; Ullman, 2001, 2004; Vaid $\&$ Genesee, 1980). The present findings of a different pattern of language laterality for people who learned two languages early in development relative to those who learned only one language presents a compelling argument that there is something special about early exposure to multiple languages that affects neurofunctional organisation.

Based on evidence that monolingual language representation is largely left lateralised, and that hemispheric growth gradients differ, it has been suggested that language may be lateralised in the left hemisphere because the left hemisphere develops more rapidly than the right during early development (Corballis, 1991). In light of our present findings, might it be that the privileged early left hemisphere growth so often observed in monolinguals is a consequence rather than an antecedent of housing only one language system, and that the right hemisphere could similarly undergo rapid early growth when multiple languages must be accommodated? Of course, this speculation would require evidence beyond the scope of this paper, but it is at least consistent with the implication of the present findings that an individual's early experience with language may anchor the pattern of functional organisation for later acquired languages. What we can conclude with reasonable confidence is that bilingualism alone is insufficient for predicting language lateralisation, as early bilinguals show bilateral activation for either language, but that the canonical pattern of left hemisphere dominance is maintained for late bilinguals, at least for the L1. Another way of framing our results is to note that language lateralisation may not differ depending on whether one $i s$ monolingual or bilingual, but on whether one was monolingual or bilingual during early development. Indeed, a separate meta-analysis that directly compared laterality of both languages within the same bilingual individuals found that early bilinguals were bilaterally activated for both languages, whereas late bilinguals were left hemisphere dominant for both languages (Hull \& Vaid, 2006). It remains for future empirical research to investigate more fully just how the patterns of brain representation for language develop in early and late bilinguals, and whether laterality in late bilinguals may vary as L2 proficiency increases.

A final area of interest addressed in the present meta-analysis is the finding that the left hemisphere is not always dominant during monolingual language processing. Although findings in the aphasia literature that monolingual patients with left hemisphere lesions regularly show language deficits has long influenced the notion of strong left hemisphere dominance 
for language, recent research has revealed more input from the right hemisphere during monolingual language processing than was previously expected (see Beeman \& Chiarello, 1998; Poeppel \& Hickok, 2004). Nevertheless, language lateralisation in healthy monolinguals has not previously been systematically assessed in the form of a meta-analysis. The present research reveals that, rather than strong left hemisphere dominance for all language activity, monolinguals exhibit only a small left hemisphere effect for language overall, and the right hemisphere is significantly involved during language processing in visual hemifield or dual task paradigms.

In summary, we offer three overarching conclusions based on the present research. First, the number of languages acquired early in life is critical for establishing the pattern of cerebral lateralisation observed in adulthood for first learned languages. Specifically, we find that monolinguals and late bilinguals, who are exposed to only one language during the first 6 years of development, are both left hemisphere dominant for language, whereas early bilinguals, who are exposed to at least two languages during the first 6 years, are bilaterally organised for language. Second, we find that although monolinguals as a group are in fact left hemisphere dominant for language, this dominance is not absolute, as the right hemisphere is also importantly engaged in monolingual language processing. Third, we show that measures of language laterality can and do provide reliable patterns of cerebral organisation for languages in monolinguals and bilinguals alike, once language experience moderators are properly controlled.

Manuscript received 20 September 2005

Revised manuscript received 16 February 2006

First published online 9 June 2006

\section{REFERENCES}

References marked with an asterisk are studies included in the metaanalysis.

Abutalebi, J., Cappa, S., \& Perani, D. (2005). What can functional neuroimaging tell us about the bilingual brain? In J. Kroll \& A. M. B. deGroot (Eds.), Handbook of bilingualism: Psycholinguistic approaches (pp. 497-515). Oxford, UK: Oxford University Press.

Albert, M., \& Obler, L. K. (1978). The bilingual brain: Neuropsychological and neurolinguistic aspects of bilingualism. New York: Academic Press.

Arthur, W., Bennett, W., \& Huffcutt, A. (2001). Conducting meta-analysis using SAS. Mahwah, NJ: Lawrence Erlbaum Associates Inc.

Beeman, M., \& Chiarello, C. (1998). Complementary left and right hemisphere language comprehension. Current Directions in Psychological Science, 7, 2-8.

Bialystok, E. (2002). Cognitive processes of L2 users. In V. Cook (Ed.), Portraits of the L2 user (pp. 147-165). Clevedon, UK: Multilingual Matters. 
Binder, J., \& Price, C. (2001). Functional neuroimaging of language. In R. Cabeza \& A. Kingstone (Eds.), Handbook of functional neuroimaging of cognition (pp. 187-252). Cambridge, MA: MIT Press.

Birdsong, D., \& Molis, M. (2001). On the evidence for maturational constraints in second-language acquisition. Journal of Memory and Language, 44 (2), 235-250.

Boatman, D. (2004). Cortical bases of speech perception: Evidence from functional lesion studies. Cognition, 92, 47-65.

Braun, A., Guillemin, A., Hosey, L., \& Varga, M. (2001). The neural organisation of discourse: An H2 15 O-PET study of narrative production in English and American Sign Language. Brain, $124,2028-2044$.

Chee, M., Hon, N., Lee, H., \& Soon, C. (2001). Relative language proficiency modulates BOLD signal change when bilinguals perform semantic judgements. NeuroImage, 13, 1155-1163.

Chee, M., Weekes, B., Lee, K., Soon, C., Schreiber, A., Hoon, J., et al. (2000). Overlap and dissociation of semantic processing of Chinese characters, English words, and pictures: Evidence from fMRI. NeuroImage, 12, 392-403.

*Chengappa, S., \& Ray, J. (2002). Hemispheric processing of concrete nouns in Kannada monolinguals and Kannada-English bilingual children and adults. Unpublished manuscript, All India Institute of Speech and Hearing, Mysore, India.

Cohen, J. (1992). A power primer. Psychological Bulletin, 112, 155-159.

Corballis, M. (1991). The lopsided ape: Evolution of the generative mind. New York: Oxford University Press.

Dijkstra, A., \& Van Heuven, W. (2002). The architecture of the bilingual word recognition system: From identification to decision. Bilingualism: Language and Cognition , 5(3), 175-197.

*Fabbro, F. (1992). Cerebral lateralisation of human languages: Clinical and experimental data. In J. Wind, B. Chiarello, \& B. Bichakjian (Eds.), Language origin: A multidisciplinary approach (pp. 195-224). London: Kluwer.

Fabbro, F. (2001). The bilingual brain: Cerebral representation of languages. Brain and Language, $79,211-222$.

*Fabbro, F., Gran, L., Basso, G., \& Bava, A. (1990). Cerebral lateralisation in simultaneous interpretation. Brain and Language, 39, 69-89.

*Fabbro, F., Gran, L., \& Bava, A. (1988). Modification in cerebral lateralisation during the acquisition of a second language (English) in adult Italian-speaking females: An experimental dichotic listening study. In A. Tartabini \& M. L. Genta (Eds.), Perspectives in the study of primates (pp. 76-85). Cosenza, Italy: DeRose.

*Furtado, J., \& Webster, W. (1991). Concurrent language and motor performance in bilinguals: A test of the age of acquisition hypothesis. Canadian Journal of Psychology, 45, 448-461.

Galloway, L. (1983). Etudes cliniques et experimentales sur la repartition hémispherique du traitement cérébral du langage chez les bilingues: Modèles théoriques. Langages, 72, 79-113.

Galloway, L., \& Krashen, S. (1980). Cerebral organisation in bilingualism and second language. In R. Scarcella \& S. Krashen (Eds.), Research in second language acquisition. Rowley, MA: Newbury House.

*Galloway, L., \& Scarcella, R. (1982). Cerebral organisation in adult second language acquisition: Is the right hemisphere more involved? Brain and Language, 16, 56-60.

Genesee, F. (1982). Experimental neuropsychological research on second language processing. TESOL Quarterly, 16, 315-321.

Genesee, F., Hamers, J., Lambert, W. E., Mononen, L., Seitz, M., \& Starck, R. (1978). Language processing strategies in bilinguals: A neuropsychological study. Brain and Language, 5, 1-12.

Goral, M., Levy, E., \& Obler, L. (2002). Neurolinguistic aspects of bilingualism. International Journal of Bilingualism, 6(4), 411-440.

*Green, A. (1986). A time-sharing cross-sectional study of monolinguals and bilinguals at different levels of second language acquisition. Brain and Cognition, 5, 477-497. 
*Green, A., Schweda-Nicholson, N., Vaid, J., White, N., \& Steiner, R. (1990). Hemispheric involvement in shadowing vs. interpretation: A time-sharing study of simultaneous interpreters with matched bilingual and monolingual controls. Brain and Language, 39, 107-133.

Hedges, L., \& Becker, B. (1986). Statistical methods in the meta-analysis of research on gender differences. In J. Hyde \& M. C. Linn (Eds.), The psychology of gender: Advance through metaanalysis. Baltimore: Johns Hopkins University Press.

Hedges, L., \& Olkin, I. (1985). Statistical methods for meta-analysis. Orlando, FL: Academic Press.

Hellige, J., \& Sergent, J. (1986). Role of task factors in visual field asymmetries. Brain and Cognition, 5, 200-222.

Hickok, G. (2001). Functional anatomy of speech perception and speech production: Psycholinguistic implications. Journal of Psycholinguistic Research, 30, 225-235.

Hickok, G., \& Poeppel, D. (2004). Dorsal and ventral streams: A framework for understanding aspects of the functional anatomy of language. Cognition, 92, 67-99.

Horwitz, B., Amunts, K., Bhattacharya, R., Patkin, D., \& Braun, A. (2001). Activation of Broca's area during language production by speech and American Sign Language: Cytoarchitectonic mapping and PET. Poster presented at annual meeting of Society for Cognitive Neuroscience, San Francisco.

Hull, R., \& Vaid, J. (2005). Clearing the cobwebs from the study of the bilingual brain: Toward converging evidence - laterality and ERP. In J. Kroll \& A. M. B. deGroot (Eds.), Handbook of bilingualism: Psycholinguistic approaches (pp. 480-496). London: Oxford University Press.

Hull, R., \& Vaid, J. (2006). How does bilingualism matter? A meta-analytic tale of two hemispheres. Manuscript submitted for publication.

Hunter, J., \& Schmidt, F. (1990). Methods of meta-analysis: Correcting error and bias in research findings. Newbury Park, CA: Sage.

*Hynd, G., \& Scott, S. (1980). Propositional and appositional modes of thought and differential speech lateralisation in Navajo Indian and Anglo children. Child Development, 51, 909-911.

Ijalba, E., Obler, L. K., \& Chengappa, S. (2004). Bilingual aphasia. In T. K. Bhatia \& W. C. Ritchie (Eds.), The handbook of bilingualism (pp. 71-89). Malden, MA: Blackwell.

Johnson, B. (1993). DSTAT 1.10: Software for the meta-analytic review of research literatures [computer software and manual]. Hillsdale, NJ: Lawrence Erlbaum Associates, Inc.

*Ke, C. (1992). Dichotic listening with Chinese and English tasks. Journal of Psycholinguistic Research, 21, 463-471.

Kim, K., Relkin, N., Lee, K., \& Hirsch, J. (1997). Distinct cortical areas associated with native and second languages. Nature, 388, 171-174.

Klein, D., Zatorre, R., Milner, B., Meyer, E., \& Evans, A. (1994). Left putamenal activation when speaking a second language: Evidence from PET. NeuroReport, 5, 2295-2297.

Kroll, J., \& Stewart, E. (1994). Category interference in translation and picture naming: Evidence for asymmetric connections between bilingual memory representations. Journal of Memory and Language, 33, 149-174.

Lambert, W. E. (1969). Psychological studies of interdependencies of the bilingual's two languages. In J. Puhvel (Ed.), Substance and structure of language (pp. 99-126). Los Angeles: University of California Press.

Lipsey, M., \& Wilson, D. (2001). Practical meta-analysis. London: Sage.

Long, M. (1990). Maturational constraints on language development. Studies in Second Language Acquisition, 12, 251-285.

Lucas, T. H., McKhann, G. M., \& Ojemann, G. A. (2004). Functional separation of languages in the bilingual brain: A comparison of electrical stimulation language mapping in 25 bilingual patients and 117 monolingual control patients. Journal of Neurosurgery, 101, 449-457.

*McClung, B. (1981). Lateralisation of a second language by monolingual and bilingual participants as determined by dichotic listening. Unpublished doctoral dissertation, Wayne State University, Detroit, MI. 
*McKeever, W., \& Hunt, L. (1984). Failure to replicate the Scott et al. finding of reversed ear dominance in the Native American Navajo. Neuropsychologia, 22 (4), 539-541.

Mechelli, A., Crinion, J., Noppeney, U., O’Doherty, J., Asburner, J., Frackowiak, R., \& Price, C. (2004). Structural plasticity in the bilingual brain. Nature, 431, 757.

Neville, H., \& Bavelier, D. (2002). Human brain plasticity: Evidence from sensory deprivation and altered language experience. In M. Hofman, G. Boer, A. Holtmaat, E. Van Someren, J. Verhaagen, \& D. Swaab (Eds.), Progress in brain research (pp. 177-188). Amsterdam: Elsevier Science.

Obler, L. K. (1981). Right hemisphere participation in second language acquisition. In K. Diller (Ed.), Individual differences and universals in language learning aptitude (pp. 53-64). Rowley, MA: Newbury.

Obler, L. K., Zatorre, R., Galloway, L., \& Vaid, J. (1982). Brain lateralisation in bilinguals: Methodological issues. Brain and Language, 15, 40-54.

Paradis, M. (1990). Language lateralisation in bilinguals: Enough already! Brain and Language, 39 , $576-613$

Paradis, M. (2003). The bilingual Loch Ness Monster raises its non-asymmetric head again - or, why bother with such cumbersome notions as validity and reliability? Comments on Evans et al. (2002). Brain and Language, 87(1), 441-448.

Poeppel, D., \& Hickok, G. (2004). Towards a new functional anatomy of language. Cognition, 92 , $1-12$.

Price, C. (1998). The functional anatomy of word comprehension and production. Trends in Cognitive Science, 2, 281-288.

Rosenthal, R. (1994). Parametric measures of effect size. In H. Cooper \& L. V. Hedges (Eds.), The handbook of research synthesis (pp. 231-244). New York: Sage.

Rosenthal, R., \& DiMatteo, M. (2001). Meta-analysis: Recent developments in quantitative methods for literature reviews. Annual Review of Psychology, 52, 59-82.

Schneiderman, E. (1986). Leaning to the right: Some thoughts on hemisphere involvement in language acquisition. In J. Vaid (Ed.), Language processing in bilinguals: Psycholinguistic and neuropsychological perspectives (pp. 233-251). Hillsdale, NJ: Lawrence Erlbaum Associates, Inc.

*Scott, S., Hynd, G., Hunt, L., \& Weed, W. (1979). Cerebral speech lateralisation in the Native American Navajo. Neuropsychologia, 17, 89-92.

Segalowitz, S. (1986). Validity and reliability of noninvasive lateralisation measures. Child Neuropsychology, 1, 191-208.

*Sewell, D., \& Panou, L. (1983). Visual field asymmetries for verbal and dot localization tasks in monolingual and bilingual participants. Brain and Language, 18, 28-34.

*Starck, R., Genesee, F., Lambert, W., \& Seitz, M. (1977). Multiple language experience and the development of cerebral dominance. In S. Segalowitz \& F. Gruber (Eds.), Language development and neurobiological theory (pp. 47-55). New York: Academic Press.

Sussman, H., \& Simon, T. (1988). The effects of gender, handedness, L1/L2 and baseline tapping rate on language lateralisation: An assessment of the time-sharing paradigm. Journal of Clinical and Experimental Psychology, 10, 69.

Ullman, M. (2001). The neural basis of lexicon and grammar in first and second language: The declarative/procedural model. Bilingualism, 4(2), 105-122.

Ullman, M. (2004). Contributions of memory circuits to language: The declarative/procedural model. Cognition, 92, 231-270.

Urbanik, A., Binder, M., Sobiecka, B., \& Kozub, J. (2001). fMRI study of sentence generation by early bilinguals differing in proficiency level. Revista di Neuroradiologia, 14(1), 11-16.

*Vaid, J. (1979). Visual field asymmetries in bilinguals on a bimodal rhyming task. Unpublished manuscript, McGill University, Montreal, Quebec, Canada. 
*Vaid, J. (1980a). Visual field asymmetries for bimodal rhyme judgements in English/French early and late bilinguals and English monolinguals. Unpublished manuscript, McGill University, Montreal, Quebec, Canada.

*Vaid, J. (1980b). Visual field asymmetries in bilinguals and monolinguals on a spatial Stroop task. Paper presented at the annual meeting of BABBLE, Niagara Falls, Ontario, Canada.

*Vaid, J. (1981a). Visual field asymmetries for rhyme and syntactic category judgements for visually presented stimuli. Unpublished manuscript, McGill University, Montreal, Quebec, Canada.

*Vaid, J. (1981b). Visual field asymmetries for rhyme judgements for visually presented stimuli. Unpublished manuscript, McGill University, Montreal, Quebec, Canada.

Vaid, J. (1983). Bilingualism and brain lateralisation. In S. Segalowitz (Ed.), Language functions and brain organisation (pp. 315-339). New York: Academic Press.

*Vaid, J. (1984a). Visual, phonetic, and semantic processing in early and late bilinguals. In M. Paradis \& Y. Lebrun (Eds.), Early bilingualism and child development (pp. 175-191). Lisse: Swets \& Zeitlinger.

*Vaid, J. (1984b). Rhyme and semantic category judgements in English/French early bilinguals and French monolinguals. Unpublished manuscript, McGill University, Montreal, Quebec, Canada.

*Vaid, J. (1987). Visual field asymmetries for rhyme and syntactic category judgements in monolinguals and fluent early and late bilinguals. Brain and Language, 30, 263-277.

Vaid, J. (2002). Bilingualism. In V. S. Ramachandran (Ed.), Encyclopedia of the human brain (pp. 417-434). San Diego, CA: Academic Press.

Vaid, J., \& Genesee, F. (1980). Neuropsychological approaches to bilingualism: A critical review. Canadian Journal of Psychology, 34, 417-445.

Vaid, J., \& Hall, D. G. (1991). Neuropsychological perspectives on bilingualism: Right, left and center. In A. Reynolds (Ed.), Bilingualism, multiculturalism, and second language learning: The McGill conference in honor of Wallace E. Lambert (pp. 81-112). Hillsdale, NJ: Lawrence Erlbaum Associates, Inc.

Vaid, J., \& Hull, R. (2002). Re-envisioning the bilingual brain using functional neuroimaging: Methodological and interpretive issues. In F. Fabbro (Ed.), Advances in the neurolinguistics of bilingualism: A festschrift for Michel Paradis (pp. 315-355). Udine, Italy: Forum.

*Vaid, J., \& Lambert, W. (1979). Differential cerebral involvement in the cognitive functioning of bilinguals. Brain and Language, 8, 92-110.

Voyer, D. (1996). On the magnitude of laterality effects and sex differences in functional lateralities. Laterality, $1(1), 51-83$.

Wood, W., \& Quinn, J. (2003). Forewarned and forearmed? Two meta-analytic syntheses of forewarnings of influence appeals. Psychological Bulletin, 129(1), 119-138. 